\title{
(6) OPEN ACCESS \\ Risk factors which predispose first-time traumatic anterior shoulder dislocations to recurrent instability in adults: a systematic review and meta-analysis
}

\author{
M Olds, ${ }^{1}$ R Ellis, ${ }^{2}$ K Donaldson, ${ }^{1}$ P Parmar, ${ }^{1}$ P Kersten ${ }^{3}$
}

\section{${ }^{1}$ Auckland University of Technology, Auckland, New Zealand \\ ${ }^{2}$ Health and Rehabilitation Research Institute, Auckland University of Technology, Auckland, New Zealand ${ }^{3}$ Centre for Person Centred Research, Auckland University of Technology, Auckland, New Zealand}

\section{Correspondence to} M Olds, Auckland University of Technology, Private Bag 92006, Auckland New Zealand;

Margie.olds@aut.ac.nz

Accepted 19 March 2015 Published Online First 21 April 2015

\section{SLinked}

- http://dx.doi.org/10.1136/ bjsports-2015-094584

\footnotetext{
To cite: Olds $M$, Ellis $R$, Donaldson $\mathrm{K}$, et al. $\mathrm{Br} J$ Sports Med Published Online First: [please include Day Month Year] doi:10.1136/ bjsports-2014-094342
}

\begin{abstract}
Background Recurrent instability following a first-time anterior traumatic shoulder dislocation may exceed $26 \%$. We systematically reviewed risk factors which predispose this population to events of recurrence.

Methods A systematic review of studies published before 1 July 2014. Risk factors which predispose recurrence following a first-time traumatic anterior shoulder dislocation were documented and rates of recurrence were compared. Pooled ORs were analysed using random-effects meta-analysis.

Results Ten studies comprising 1324 participants met the criteria for inclusion. Recurrent instability following a first-time traumatic anterior shoulder dislocation was $39 \%$. Increased risk of recurrent instability was reported in people aged 40 years and under $(O R=13.46)$, in men $(O R=3.18)$ and in people with hyperlaxity $(O R=2.68)$. Decreased risk of recurrent instability was reported in people with a greater tuberosity fracture $(O R=0.13)$. The rate of recurrent instability decreased as time from the initial dislocation increased. Other factors such as a bony Bankart lesion, nerve palsy and occupation influenced rates of recurrent instability.

Conclusions Sex, age at initial dislocation, time from initial dislocation, hyperlaxity and greater tuberosity fractures were key risk factors in at least two good quality cohort studies resulting in strong evidence as concluded in the GRADE criteria. Although bony Bankart lesions, Hill Sachs lesions, occupation, physiotherapy treatment and nerve palsy were risk factors for recurrent instability, the evidence was weak using the GRADE criteria-these findings relied on poorer quality studies or were inconsistent among studies.
\end{abstract}

\section{INTRODUCTION}

Shoulder dislocations are a significant and costly problem. Overall incidence rates of shoulder dislocations varies between $23.9^{1}$ and $23.1^{2}$ per 100000 person-years with a higher incidence rate in young men (98.3 per 100000 person-years). ${ }^{2}$ Traumatic shoulder dislocations in males under the age of 30 years cost New Zealand approximately five million dollars per year, with 3886 new injuries reported from April 2012 to March 2013 (Personal Communication, ACC Statistics, 2013). The total cost to the health service of these claims over this period is almost NZ\$8 million. Real additional costs include time off work/school and impact on family members for care. When a first-time traumatic anterior shoulder dislocation develops into recurrent instability, additional emotional and financial costs can be substantial. Reported rates of instability vary between $26 \%{ }^{3}$ and $100 \% .^{4}$
Some authors have proposed immediate stabilisation for young athletes following a dislocation. ${ }^{5-7}$ Others $^{8}$ have proposed that this will result in unnecessary surgical intervention for those who are not at risk of developing further instability. Consequently, better decision-making regarding immediate surgical stabilisation at the time of first dislocation is a desirable goal for both patients and the wider society.

It has also been argued that there is a need to identify modifiable risk factors for recurrent shoulder instability following a first-time traumatic anterior shoulder dislocation. ${ }^{9}{ }^{10}$ Extrinsic risk factors of recurrent shoulder instability include occupations which involve using the upper limb above chest height, ${ }^{8}$ collision sport ${ }^{11}$ or playing surface. ${ }^{12}$ Intrinsic risk factors include hypermobility ${ }^{12-14}$ and age. ${ }^{15}$ Some intrinsic risk factors may be the result of pathological damage which had occurred during a dislocation. A first-time traumatic anterior shoulder dislocation may also predispose patients to recurrent instability. ${ }^{11} 1617$ However, much of the evidence which supports these risk factors is based on clinical opinion or cross-sectional studies. ${ }^{18}$

Therefore, we aimed to identify the risk factors which predict the development of recurrent shoulder instability in adults within one or more years following a first-time traumatic anterior shoulder dislocation. Data from this review will be used in a later study to develop and validate a predictive tool of recurrence after first-time traumatic anterior shoulder dislocation.

\section{METHODS}

The systematic review was carried out in accordance with the PRISMA (Preferred Reporting Items for Systematic Reviews and Meta-Analyses) protocol and registered with the PROSPERO database (registration number: CRD42013005900).

\section{Literature search}

A search strategy (table 1) was developed, combined with the Boolean term 'AND', and then used by one reviewer (MO) to search the following databases: Biomedical Reference Collection, CINAHL, MEDLINE, Sports Discus, AMED, EBM Reviews, ERIC, Health and Psychosocial instruments, Proquest, Web of Science and SCOPUS. Potential articles were identified by screening titles and abstracts, and if these met the inclusion criteria, the full text of the articles were obtained. Reference lists of these articles were cross-referenced for other articles of interest and used to help refine the inclusion and exclusion criteria. To exclude the 
Table 1 Keywords used in the search strategy

1 (shoulder* ADJ5 instabil $^{*}$ ) OR (shoulder* ADJ5 dislocat*) OR (shoulder* ADJ5 stabil*) OR (shoulder* ADJ5 sublux*) OR (shoulder* ADJ5 unstab*) OR (glenohumeral ADJ5 instabil*) OR (glenohumeral ADJ5 dislocat*) OR (glenohumeral ADJ5 stabil*) OR (glenohumeral ADJ5 sublux*) OR (glenohumeral ADJ5 unstab*) OR (GHJ ADJ5 instabil*) OR (GHJ ADJ5 dislocat*) OR (GHJ ADJ5 stabil*) OR (GHJ ADJ5 sublux*) OR (GHJ ADJ5 unstab*)

2 Recurr* OR reocurr ${ }^{*}$ OR redislocat* ${ }^{*}$ OR repeat*

3 Risk* OR factor* OR prevalen* OR predict* OR incidence OR "odds ratio"

*Indicates truncation of search term.

possibility of publication bias, such as the publication of only positive findings, grey literature was searched for theses and other trials.

\section{Inclusion and exclusion criteria}

Studies were included if they were prospective and retrospective cohort studies, which investigated risk factors for developing recurrent instability following a first-time traumatic anterior shoulder dislocation. Cohort designs were chosen because of the ability to infer causation and the ability to examine multiple risk factors. For the purpose of this review, recurrent instability was defined as a repeated instability event of either a subluxation or a dislocation. Studies were included if the subluxation or dislocation was confirmed by either radiological evidence or clinical testing and rate of recurrence was documented as an outcome measure. Studies were also included if they had a follow-up of 1 year or more as Robinson et $a l^{11}$ have shown a decrease in the incidence of shoulder instability events after 12 months. Studies were included if they were published before 1 July 2014.

Studies were excluded if the follow-up period was less than 12 months; they reported posterior, ${ }^{19}$ multidirectional or atraumatic shoulder instability; ${ }^{4}$ or patients were under the age of 15 years. $^{20}$ Age restrictions were applied in this review as children with open physes may present with different pathoanatomy following a dislocation. ${ }^{20}$ Additionally, the open physes itself may also represent a specific risk factor. ${ }^{20}$ Studies which investigated risk factors of recurrent instability following surgical intervention or compared alternative surgical interventions were also excluded, as this population is different from those with first-time traumatic anterior shoulder dislocation that have not undergone surgical intervention.

\section{Assessment of study quality}

The methodological quality of each of the included studies was evaluated by two reviewers (MO and $\mathrm{KD}$ ), using the SIGN (Scottish Intercollegiate Guidelines Network) for cohort studies. The SIGN checklist examines the internal validity of the study and includes factors such as participant selection, confounding and assessment. The overall methodological quality of each article is graded as high quality $(++)$, acceptable $(+)$ or low quality (0). ${ }^{21}$ The SIGN checklist is reported to be the most appropriate and valid tool for assessing the methodological quality of observational studies. ${ }^{22}$ One question (1.4) examines the likelihood that some participants might already have recurrent instability at the time of enrolment. This question was excluded as it was not possible for eligible studies to have the recurrent instability at the time of enrolment as these studies all examined a first-time dislocation. Disagreements between reviewers were resolved in a single consensus meeting. If consensus could not be reached, a separate independent author
(PK) was used to reach a decision of the methodological quality as recommended by the SIGN50 handbook. ${ }^{23}$ No articles were excluded from analysis based on quality scores. Scales have been shown to provide unreliable assessments of validity ${ }^{24}$ and have been explicitly discouraged in the Cochrane handbook. ${ }^{25}$

\section{Data extraction and synthesis}

Data from included studies were extracted, including patient demographics, rate of recurrent instability, mechanism of injury, pathological factors associated with recurrent instability and any other factor associated with recurrent instability. If these data were not available, or the methods required clarification, the authors were contacted. Articles were excluded from further analysis when the authors could not be contacted or the authors were unable to provide the information on request. Studies that were published in a language other than English were translated. Data were pooled and recurrent instability was reported as a percentage across all studies which reported the variable.

A meta-analysis was performed to compare the rates of recurrent shoulder instability of patients in the included studies using Comprehensive Meta-Analysis Software. ${ }^{26}$ Studies where the calculation of an OR was possible were included in the meta-analysis. For each available variable, pooled dichotomous data were analysed using random-effects meta-analyses and ORs. Heterogeneity was reported using the $\mathrm{I}^{2}$ index, where a larger score indicates a greater proportion of the variability could be attributed to heterogeneity. ${ }^{27}$ Significance was set at $\mathrm{p}<0.05$.

\section{RESULTS}

The initial search resulted in 1195 citations. An additional three studies were found by cross-referencing the bibliographies of fulltext articles. Most of the studies (99\%) were excluded as they did not meet the inclusion criteria outlined above. For example, many did not use a cohort study design, did not provide sufficient details of the first dislocation or only followed up patients for a short duration. Ten studies comprising 1324 participants were included in the review and data extraction (figure 1 ). There were more male than female patients in the studies (966 vs 358) and ages ranged from 15 to 96 years (table 2).

Two studies ${ }^{8} 11$ were rated as high quality, three studies 31628 as acceptable and five $\mathrm{e}^{1529-32}$ as low (table 3). Seven ${ }^{315} 16$ 28-31 studies were of retrospective design. The remaining three studies were of prospective design. ${ }^{8} 1132$ Common strengths of the studies were the representative nature of the sample to the wider population, and follow-up of participants. Weaknesses across the studies included a lack of an explicit definition of recurrence, lack of reported confounding factors or analysis of these factors and lack of blinding to risk factors in the follow-up. Studies that reported arm dominance $\begin{array}{llll}8 & 30 & 31 & \text { or }\end{array}$ affected side ${ }^{16}$ failed to find an association between these variables and recurrent instability.

\section{Age}

All 10 studies examined age as a risk factor for recurrent instability (table 4) and found an association between age and instability. Some studies had previously grouped data for those 40 years and younger, and they were unable to provide raw data. Therefore, these data were grouped into two age brackets 15-40 years and greater than 40 years. This shows increased rates of recurrence in those 40 years and less (44\%) compared with those over the age of $40(11 \%)$. There is increased risk of recurrence for those aged 40 or below, compared with those aged over the age of $40(\mathrm{OR}=13.46,95 \% \mathrm{CI}(5.25$ to 34.49$)$, $\mathrm{Z}=5.41, \mathrm{p}<0.001, \mathrm{I}^{2}=63.18$; figure 2$)$. Further analysis of the 


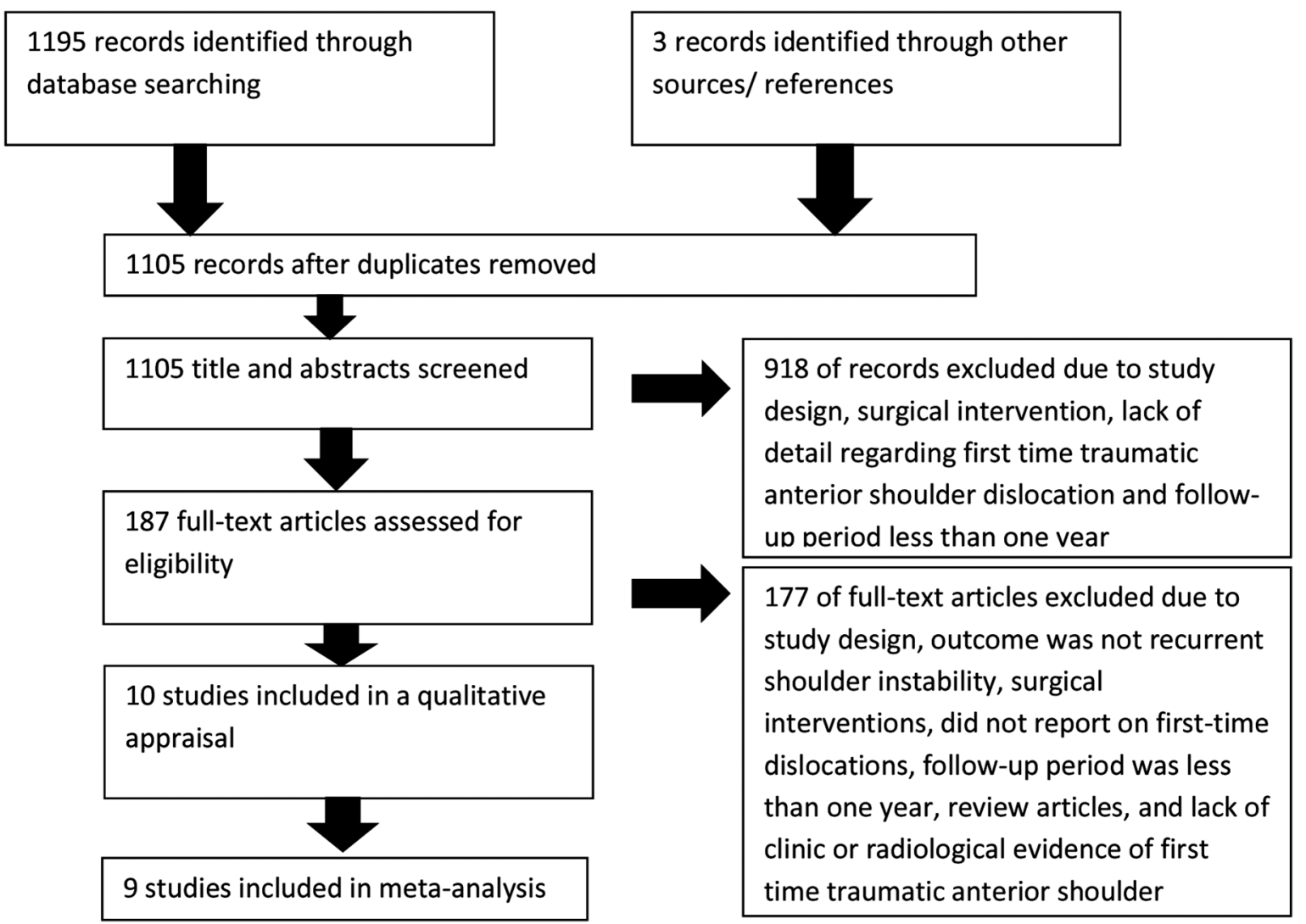

Figure 1 Flow diagram of article selection according to PRISMA.

association between age at first dislocation and rate of recurrent instability is undertaken in tables 5 and 6 . This table shows that the rate of recurrent instability in those aged between 15-20 and 15-30 years is approximately 50\%. Lower rates of recurrence are seen in people aged between 41 and 60 years and those aged over 61 years, and the rate does not vary greatly between these two groups.

\section{Sex}

Seven studies ${ }^{3} 1116$ 29-32 reported the effect of sex on recurrent shoulder instability with an overall rate of recurrence of $46.84 \%$ in men compared with $27.22 \%$ in women (tables 5 and 6). Six studies compared rates of recurrent instability in men with women and men were found to be over three times more at risk of recurrent instability $(\mathrm{OR}=3.18,95 \%$ CI $(1.28$ to 7.89$)$, $\mathrm{Z}=2.49, \mathrm{p}=0.01, \mathrm{I}^{2}=75.53$; figure 3 ). One study included only men and so did not compare recurrence between sexes. ${ }^{32}$ Five studies $^{3} 11 \quad 163032$ reported rates of recurrent instability across sexes in people aged under 40 years and found the rates of recurrence to be similar to the total recurrence. Three studies $^{3} 1630$ reported that there were more women with an initial dislocation aged over 40 years compared with the number of women aged 40 years and under. Te Slaa et $a l^{3}$ reported that rates of recurrent instability in those aged over 40 years were similar in men and women (22\% and 25\%, respectively). No further analysis of recurrent instability in men compared with women over the age of 40 was undertaken.

\section{Mechanism of injury}

Mechanism of injury was reported in nine studies. 38111516 29-32 Many authors reported a direct blow or fall as a mechanism of initial dislocation. Other mechanisms of injury included assaults and seizures ${ }^{11}$ or motor vehicle accidents. ${ }^{11}{ }^{16}$ Meta-analysis was not possible due to large variation in the definition of mechanism of injury.

Many authors reported the initial dislocation to occur during an athletic activity, particularly in the younger age group. Simonet and Cofield ${ }^{16}$ reported that $77 \%$ of those younger than 30 years of age suffered a recurrent instability event due to a sporting activity. Two low-quality studies ${ }^{15}{ }^{30}$ reported no significant difference in the rate of recurrent instability in the type of sport played following the first-time traumatic anterior shoulder dislocation. A higher quality study ${ }^{8}$ found a non-significant relationship between recurrent instability and those involved in contact or collision sports despite a trend towards significance and more requests for surgery in those involved in contact or collision sports $(p=0.105, \mathrm{OR}=7.846)$. There was a trend between return to sport or full activities of daily living within 6 weeks of a first-time traumatic anterior shoulder dislocation $(p=0.082)$ and a return to sport within the first year after a first-time traumatic anterior shoulder dislocation $(p=0.095)$ with respect to recurrent instability. ${ }^{11}$ Simonet and Cofield ${ }^{16}$ also reported that $56 \%$ of those who returned to sport or full activity within 6 weeks and were under the age of 30 years suffered from recurrent instability.

\section{Pathological features}

Six studies $\begin{array}{llllll}11 & 15 & 28 & 30 & 31 & \text { examined the effect of concomitant }\end{array}$ pathology on recurrent instability and five 311153031 found the presence of a greater tubercle fracture decreased the risk of recurrence. The data showed that people with a greater tuberosity fracture were over seven times less likely to suffer from 
Table 2 Quality rating of studies included in the review according to the SIGN scale, which assesses the risk of bias and confounding present and the ability of the study to establish a causal relationship between the variables of interest and recurrent shoulder instability

\begin{tabular}{|c|c|c|c|c|c|c|c|c|c|c|c|c|c|c|c|c|c|}
\hline $\mathrm{SIGN}^{21}$ & $\begin{array}{l}\text { Clear } \\
\text { focused } \\
\text { question }\end{array}$ & $\begin{array}{l}\text { Selection } \\
\text { bias }\end{array}$ & $\begin{array}{l}\text { Selection } \\
\text { bias }\end{array}$ & $\begin{array}{l}\text { Performance } \\
\text { bias }\end{array}$ & $\begin{array}{l}\text { Attrition } \\
\text { bias }\end{array}$ & $\begin{array}{l}\text { Attrition } \\
\text { bias }\end{array}$ & $\begin{array}{l}\text { Detection } \\
\text { bias }\end{array}$ & $\begin{array}{l}\text { Detection } \\
\text { bias }\end{array}$ & $\begin{array}{l}\text { Detection } \\
\text { bias }\end{array}$ & $\begin{array}{l}\text { Detection } \\
\text { bias }\end{array}$ & $\begin{array}{l}\text { Detection } \\
\text { bias }\end{array}$ & $\begin{array}{l}\text { Detection } \\
\text { bias }\end{array}$ & Confounding & $\mathrm{Cl}$ & $\begin{array}{l}\text { Limitation } \\
\text { of bias }\end{array}$ & & \\
\hline Author & 1.1 & 1.2 & 1.3 & 1.4 & 1.5 & 1.6 & 1.7 & 1.8 & 1.9 & 1.1 & 1.11 & 1.12 & 1.13 & 1.14 & 2 & Rating† & Total¥ \\
\hline teSlaa et $a l^{\beta}$ & 1 & 1 & & & & & 0 & 1 & 1 & 0 & 0 & & 1 & $\mathrm{~N}$ & + & Acceptable & 5 \\
\hline $\begin{array}{l}\text { Simonet and } \\
\text { Cofield }^{16}\end{array}$ & 1 & 1 & & & & & 1 & 1 & 0 & 0 & 0 & & 1 & $N$ & + & Acceptable & 5 \\
\hline Safran et $\left.a\right|^{32}$ & 1 & 1 & 0 & & 1 & 1 & 1 & 0 & 0 & 1 & 0 & 1 & 0 & $Y$ & - & Low & 7 \\
\hline Sachs et $a l^{8}$ & 1 & 1 & 1 & & 1 & 0 & 1 & 1 & 1 & 0 & 0 & 1 & 1 & $Y$ & + & High & 9 \\
\hline $\begin{array}{l}\text { Robinson } \\
\text { et } a l^{11}\end{array}$ & 1 & 1 & 1 & & 1 & 1 & 1 & 0 & 0 & 1 & 1 & 1 & 1 & Y & + & High & 10 \\
\hline $\begin{array}{l}\text { Kralinger } \\
\text { et } a 1^{15}\end{array}$ & 1 & 0 & & & & & 0 & 0 & 0 & 1 & 1 & & 1 & $N$ & - & Low & 4 \\
\hline $\begin{array}{l}\text { Vermeiren } \\
\text { et } a^{\beta 1}\end{array}$ & 1 & 1 & & & & & 0 & 0 & 0 & 0 & 0 & & 0 & $\mathrm{~N}$ & - & Low & 2 \\
\hline Hoelen et $a \beta^{30}$ & 1 & 1 & & & & & 1 & 0 & 0 & 0 & 0 & & 0 & $\mathrm{~N}$ & - & Low & 3 \\
\hline $\begin{array}{l}\text { Salomonsson } \\
\text { et } a^{28}\end{array}$ & 1 & 1 & & & & & 1 & 1 & 1 & 1 & 0 & & 1 & $\mathrm{~N}$ & + & Acceptable & 7 \\
\hline Pevny et $a l^{29}$ & 1 & 1 & & & & & 1 & 1 & 0 & 1 & 0 & & 0 & $\mathrm{~N}$ & - & Low & 5 \\
\hline
\end{tabular}

*Grey shading indicates retrospective studies where it was not possible to evaluate criteria.

tRating scales refer to how well the study has minimised the risk of bias or confounding and establish a causal relationship between the risk factor and recurrent instability. High-quality studies have little or no risk of bias, and the results from these studies are unlikely to change with further research. Acceptable quality studies have some associate risk of bias and the conclusions may change in light of further studies. Low-quality studies have significant flaws related to study design and the conclusions drawn from these studies are likely to change in the light of further studies.

₹Total scores can range from 0 to 13 with lower number representing increased risk of bias and higher numbers representing prospective cohort studies with minimal risk of bias.

N, no; SIGN, Scottish Intercollegiate Guidelines Network; Y, yes. 
Table 3 Demographic data of the 10 included studies

\begin{tabular}{|c|c|c|c|c|c|c|c|c|c|}
\hline & $\begin{array}{l}\text { Total } \\
\text { participant }\end{array}$ & $\begin{array}{l}\text { Total } \\
\text { recurrence } \\
(\%)\end{array}$ & Age (range) & $\begin{array}{l}\text { Dominant } \\
\text { dislocation } \\
\text { (side) }\end{array}$ & Male & Female & $\begin{array}{l}\text { Male } \\
\text { recurrence }\end{array}$ & $\begin{array}{l}\text { Female } \\
\text { recurrence }\end{array}$ & $\begin{array}{l}\text { Study } \\
\text { design }\end{array}$ \\
\hline Robinson et $a l^{11}$ & 252 & 60 & 15-35 years & NR & 225 & 27 & $39 \%$ & $7 \%$ & Prospective \\
\hline Salomonsson et al ${ }^{28}$ & 51 & 52 & $17-69$ years & $57 \%$ & 42 & 9 & NR & NR & Prospective \\
\hline $\begin{array}{l}\text { Simonet and } \\
\text { Cofield }^{16}\end{array}$ & 116 & 33 & 20-96 years* & $\begin{array}{l}58(R), 66 \\
(L)\end{array}$ & 82 & 34 & NR & NR & Retrospective \\
\hline Sachs et $a l^{8}$ & 131 & 33 & 20-82 years* & $40 \%$ & 102 & 29 & NR & NR & Prospective \\
\hline teslaa et $a l^{3}$ & 107 & 74 & 20-88 years* & NR & 69 & 38 & $71 \%$ & $79 \%$ & Retrospective \\
\hline Vermeiren et $a l^{31}$ & 154 & 25 & $15-85$ & NR & 82 & 72 & $32 \%$ & $18 \%$ & Retrospective \\
\hline Kralinger et $a l^{15}$ & 241 & 23 & $13-86$ & $42 \%$ & 176 & 65 & NR & NR & Retrospective \\
\hline Hoelen et $a l^{\beta 0}$ & 168 & 26 & $15-94$ & $53 \%$ & 96 & 72 & $40 \%$ & $8 \%$ & Retrospective \\
\hline Pevny et $a l^{29}$ & 52 & 4 & $40-79$ & NR & 40 & 12 & $5 \%$ & $0 \%$ & Retrospective \\
\hline \multirow[t]{2}{*}{ Safran et $a l^{32}$} & 52 & 46 & $17-27$ & NR & 52 & 0 & $46 \%$ & $0 \%$ & Prospective \\
\hline & 1324 & 39 & $15-96$ & & 966 & 358 & $47.30 \%$ & $25.50 \%$ & \\
\hline
\end{tabular}

recurrent instability compared with those without a fracture $(\mathrm{OR}=0.13,95 \%$ CI $(0.06$ to 0.30$), \mathrm{Z}=-4.99, \mathrm{p}<0.0001$, $\mathrm{I}^{2}=0.00$; figure 4$)$. The presence of a bony Bankart lesion was also found to have a protective effect against recurrent instability, although this was not significant $(\mathrm{OR}=0.51,95 \% \mathrm{CI}(0.17$ to 1.52$), \quad Z=-1.2, \quad p=0.23, \quad I^{2}=19.6$; figure 5). Three studies $^{15} 2830$ examined Hill Sachs lesions, although one lowquality study ${ }^{15}$ reported Hill Sachs lesions in all participants, preventing the calculation of an OR. Data from the remaining two studies ${ }^{28} 30$ show that people are 1.55 times more likely to have recurrent instability in the presence of a Hill Sachs lesions compared with people who do not have a Hills Sachs lesion $(\mathrm{OR}=1.55,95 \%$ CI $(0.14$ to 17.63$), \mathrm{Z}=0.356, \mathrm{p}=0.72$, $\left.\mathrm{I}^{2}=61.51\right)$. These results are not significant and there is a large degree of variability between the studies. Two studies ${ }^{11}{ }^{29}$ compared the effect of a nerve palsy on recurrent instability with no nerve palsy and data showed that people with a nerve palsy are 2.49 times less likely to suffer from recurrent instability in the presence of a nerve palsy (OR $=0.40,95 \%$ CI (0.043 to 3.762$)$, $\mathrm{Z}=-0.80, \mathrm{p}=0.42, \mathrm{I}^{2}=45.57$; figure 6 ).

\section{Other risk factors for recurrent instability}

Four studies ${ }^{15} 163031$ examined treatment options following a first-time traumatic anterior shoulder dislocation. No significant difference in the rate of recurrent instability was found related to the reduction method or type of immobilisation, ${ }^{16}$ or the period of immobilisation. ${ }^{30}$ Two studies examined the effect of physical therapy of recurrent instability. Vermeiren et $a l^{31}$ reported that those with recurrent instability reported an average of 15 daily sessions of intensive exercises with a physiotherapist, which was considerably less than those in the nonrecurrent group (47 daily sessions). In contrast, Kralinger et al ${ }^{15}$ found that the age-adjusted rate of participation in physical therapy showed no association with recurrent instability. Time from the initial dislocation appears to affect recurrent instability as most subsequent episodes occurred within 2 years of the initial dislocation. ${ }^{3} 811{ }^{16}$ One good quality ${ }^{11}$ and one acceptable study $^{28}$ examined hyperlaxity and the data show that people with hyperlaxity are 2.68 times more likely to experience recurrent instability compared with those without hyperlaxity $(\mathrm{OR}=2.68,95 \% \mathrm{CI}(1.33$ to 5.39$), \mathrm{Z}=2.76, \mathrm{p}=0.0057$, $\mathrm{I}^{2}=0.00$; figure 7). Occupation was a factor in recurrent instability as Sachs et $a l^{8}$ reported that those who worked with their arms above chest height were more likely to suffer from recurrent instability $(\mathrm{p}=0.006, \mathrm{OR}=5.762)$. Vermeiren et al ${ }^{31}$ similarly examined occupation and reported that manual labourers had a recurrence rate of $31 \%$ compared with other professions (students, retired people and housewives; 24\%). Kralinger et $a l^{15}$ reported that those who had recurrent instability had $0.44^{\circ}$ of loss of external rotation at $90^{\circ}$ of abduction compared with those without recurrence $(p=0.044)$. Finally, Safran $e t a l^{32}$ examined the predictive ability of the apprehension test at 6 weeks following a dislocation and found that a negative test was significantly related to recurrent instability $(\mathrm{OR}=4.286,95 \%$ CI $(1.129$ to 16.266$), \mathrm{p}=0.03)$. However, the test was not significant in predicting the length of time to dislocation.

\section{DISCUSSION}

Many studies have reported the rate of recurrent instability following a first-time traumatic anterior shoulder dislocation to be over 75\%. ${ }^{33}$ Many variables influence recurrent instability such as sex, age, laxity and other pathological lesions. Across all these variables, our study showed the rate of recurrent instability 1 year after a first-time traumatic anterior shoulder dislocation was $39 \%$.

\section{What is the true rate of recurrence after first-time shoulder dislocation?}

The rate of $39 \%$ is a great deal lower than other studies, which have compared patients treated non-surgically compared with those treated surgically. ${ }^{33} \quad 35$ These clinical studies ${ }^{7} \quad 33 \quad 35$ excluded a large proportion of participants due to poor recruitment methods (eg, only including the participants who present for medical treatment and ignoring those who do not contact medical professionals). The strict inclusion and exclusion criteria necessary for rigorous randomised controlled trials (RCTs) can result in study populations which are not representative of the general population as only those participants with pathological lesions are entered into the trial, and therefore data may be skewed in favour of surgical stabilisation. Prospective cohort studies are ideal to accurately identify risk factors for recurrent instability. ${ }^{36}$ These study designs do not exclude any participant who has had a first-time traumatic anterior shoulder dislocation 


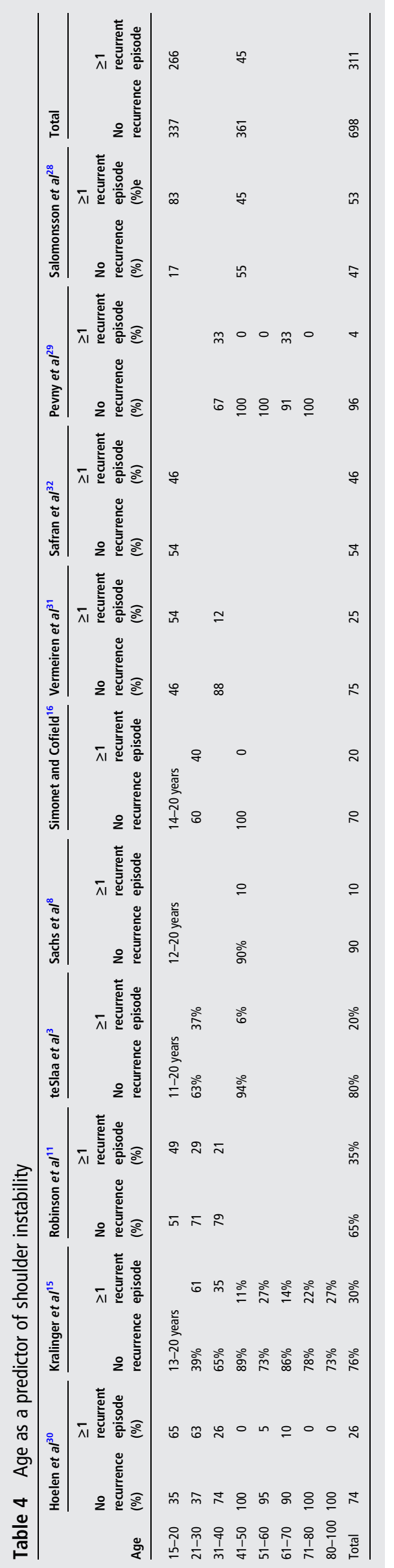

and consequently provide a more complete picture of the risk factors for this population. Three other seminal papers have reported similar results with regard to rates of recurrent shoulder instability as found in this review. ${ }^{47} 38$ However, one was a prospective intervention study, ${ }^{37}$ one included both traumatic and atraumatic dislocations, ${ }^{4}$ and one did not have an adequate follow-up period. ${ }^{38}$ These studies therefore did not reach the inclusion criteria required to examine this topic and were excluded from the review.

\section{Key risk factors-age, sex and mechanism of injury}

Men were found to have increased risk of recurrence compared with women. There may be an interaction between sex and other risk factors such as neuromuscular factors ${ }^{39}$ or mechanism of injury. For example, men may be more likely to sustain an instability event during contact with a sporting opponent. ${ }^{39}$ Furthermore, studies in collision sports may have a sex bias and many traditional collision sports have modified rules in the women's version. ${ }^{40}$ Further examination is required to understand the effect of confounding variables such as contact sports, before alteration in clinical practice is advocated.

All studies included in this review found that age was associated with recurrent instability with people aged 40 years and under 13.46 times more likely to suffer from recurrent instability, compared with those over the age of 40 years. This may be due to differences in biomechanical properties, ${ }^{41}$ collagen fibre type,${ }^{42}$ elasticity of the capsule ${ }^{43}$ or changes in activity level ${ }^{4}$ as a function of age. The effect of mechanism of injury was difficult to quantify as authors grouped the mechanism differently. Some authors grouped sporting activity as a mechanism of injury $^{81131}$ when perhaps it would have been more accurate to have described the actual mechanism itself, for example, imposed force from another person. Sporting injuries may have also encompassed falls under $2 \mathrm{~m},{ }^{11}$ creating confusion regarding categorisation. There was a lack of significant findings to show an association between participation in contact sport or early return to sport following a first-time traumatic anterior shoulder dislocation. It is possible that the number of people involved in contact or collision sports in this study, compared with other or no sports, prevented these result reaching significance.

\section{Risk factors related to the injury itself}

Of interest is the protective effect that some pathological variables had on recurrent instability. The presence of a greater tuberosity fracture was found to decrease the rate of recurrent instability by over seven times. Kralinger $e t \mathrm{al}^{15}$ postulated that this was due to decreased range of external rotation in abduction as those with a loss of external rotation in neutral had decreased risk of recurrence. An axillary nerve palsy similarly does not affect the structural integrity of the joint, and this lesion was also found to decrease the risk of recurrent instability. Furthermore, both tubercle fractures and axillary palsies result in decreased movement of the limb for a significant period of time, which may increase the strength of the anatomical repair and limit exposure to high-risk dislocation positions such as abduction/external rotation. ${ }^{15}$ Other authors ${ }^{44}$ have proposed that lesions which involve the glenoid labrum result in increased rates of recurrent instability. There was a trend towards increased risk of recurrent instability in people with a Hill Sachs lesion. Further prospective investigation is required to investigate whether the size of a Hill Sachs lesion has an impact on recurrent instability. ${ }^{15}$ 
Study name

Hoelen et al., 1990

Kralinger et al., 2002

te Slaa et al., 2003

Simonet and Cofield, 1984

Vermeiren et al., 1993

Salomonnsson et al., 2009

Pevny et al., 1998
Statistics for each study

Odds Lower Upper

ratio limit limit $Z$-Value $p$-Value

$\begin{array}{lllll}26.471 & 8.803 & 79.597 & 5.832 & 0.000\end{array}$

$\begin{array}{lllll}3.913 & 1.900 & 8.057 & 3.702 & 0.000\end{array}$

$\begin{array}{lllll}9.284 & 2.478 & 34.783 & 3.307 & 0.001\end{array}$

$\begin{array}{lllll}54.811 & 3.161 & 950.471 & 2.751 & 0.006\end{array}$

$\begin{array}{lllll}244.574 & 14.398 & 4154.638 & 3.805 & 0.000\end{array}$

$\begin{array}{lllll}5.760 & 1.605 & 20.670 & 2.686 & 0.007\end{array}$

$\begin{array}{lllll}22.000 & 0.978 & 494.760 & 1.946 & 0.052\end{array}$

$\begin{array}{lllll}13.459 & 5.252 & 34.492 & 5.414 & 0.000\end{array}$
Odds ratio and $95 \% \mathrm{Cl}$

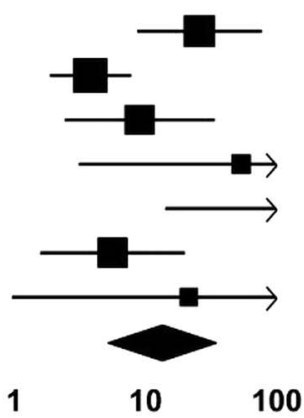

Favours $\mathbf{4 0}$ years and under

Table 5 Percentage of recurrence across age group

\begin{tabular}{|c|c|c|c|c|c|}
\hline Age range (years) & Number of studies & $\begin{array}{l}\text { Total number } \\
\text { recurrence }\end{array}$ & Total recurrence & Total number & $\begin{array}{l}\text { Percentage } \\
\text { recurrence }(\%)\end{array}$ \\
\hline $15-20$ & 2 studies $^{11} 30$ & 53 & 56 & 109 & 51 \\
\hline $15-30$ & 6 studies $^{11} 1528$ 30-32 & 224 & 211 & 435 & 49 \\
\hline $21-40$ & 7 studies $^{3} 11151629-31$ & 319 & 147 & 413 & 36 \\
\hline $41+$ & 7 studies $^{3} 8151628-30$ & 737 & 41 & 389 & 11 \\
\hline $41-60$ & 3 studies $^{1529} 30$ & 109 & 13 & 122 & 11 \\
\hline $61+$ & 3 studies $^{152930}$ & 102 & 11 & 113 & 10 \\
\hline
\end{tabular}

The finding of decreased recurrent instability in the presence of a bony Bankart was surprising. Robinson et $a l^{45}$ followed participants for 6 weeks following a first-time traumatic anterior shoulder dislocation and reported increased risk of recurrence in the presence of a glenoid rim fracture $(R R=7.0)$ and in the presence of both a Hill Sachs lesion and glenoid rim fracture $(R R=33.5)$. However, a 1 year follow-up of the same cohort reported no analysis related to glenoid rim fractures and the 10 people who underwent surgical stabilisation as a result of a glenoid rim fracture associated with subluxation were excluded from the cohort. Similarly, Salomonsson et al ${ }^{28}$ excluded people with large bony Bankart lesions who had difficulty maintaining stability following a closed reduction. Further examination of the bony Bankart size, location and interaction with Hill Sachs lesions (eg, glenoid track) ${ }^{46}$ is required in a prospective cohort study.

Table 6 Sex as a predictor for recurrent shoulder instability

\begin{tabular}{|c|c|c|c|c|c|c|c|c|}
\hline & $\begin{array}{l}\text { Total } \\
\text { participants }\end{array}$ & $\begin{array}{l}\text { Total } \\
\text { recurrence } \\
(\%)\end{array}$ & $\begin{array}{l}\text { Number } \\
\text { of men }\end{array}$ & $\begin{array}{l}\text { Number of } \\
\text { women }\end{array}$ & $\begin{array}{l}\text { Total } \\
\text { recurrence } \\
\text { in men (\%) }\end{array}$ & $\begin{array}{l}\text { Total } \\
\text { recurrence } \\
\text { in women (\%) }\end{array}$ & $\begin{array}{l}\text { Recurrence } \\
\text { in men } \\
<40 \text { years (\%) }\end{array}$ & $\begin{array}{l}\text { Recurrence } \\
\text { in women } \\
<40 \text { years (\%) }\end{array}$ \\
\hline Robinson et al ${ }^{11}$ & 252 & 60 & 225 & 27 & 39 & 7 & 39 & 7 \\
\hline Salomonsson et $\mathrm{al}^{28}$ & 51 & 52 & 42 & 9 & & & & \\
\hline Simonet and Cofield ${ }^{16}$ & 116 & 33 & 82 & 34 & 49 & 12 & 49 & 40 \\
\hline Sachs et $a l^{8}$ & 131 & 33 & 102 & 29 & & & & \\
\hline teSlaa et $a l^{3}$ & 107 & 74 & 69 & 38 & 71 & 79 & 91 & 36 \\
\hline Vermeiren et $a l^{\beta 1}$ & 154 & 25 & 82 & 72 & 30 & 18 & & \\
\hline Kralinger et $a l^{15}$ & 241 & 23 & 176 & 65 & & & & \\
\hline Hoelen et $a^{\beta 0}$ & 168 & 26 & 96 & 72 & 40 & 8 & 65 & 57 \\
\hline Pevny et $a l^{29}$ & 52 & 4 & 40 & 12 & 5 & 0 & & \\
\hline Safran et $a \beta^{32}$ & 52 & 46 & 52 & 0 & 46 & 0 & 46 & 0 \\
\hline $\begin{array}{l}\text { Total values and mean } \\
\text { percentage }\end{array}$ & 657 & 39 & 966 & 358 & 47.30 & 25.50 & 46.84 & 22.22 \\
\hline
\end{tabular}


Study name

$\begin{array}{lcccrr} & \begin{array}{c}\text { Odds } \\ \text { ratio }\end{array} & \begin{array}{c}\text { Lower } \\ \text { limit }\end{array} & \begin{array}{c}\text { Upper } \\ \text { limit }\end{array} & \text { Z-Value } & \text { p-Value } \\ \text { Hoelen et al., 1990 } & 7.526 & 2.970 & 19.070 & 4.255 & 0.000 \\ \text { Pevny et al., 1998 } & 1.364 & 0.061 & 30.638 & 0.195 & 0.845 \\ \text { Robinson et al., 2006 } & 7.880 & 1.821 & 34.105 & 2.762 & 0.006 \\ \text { Simonet \& Cofield, 1984 } & 7.143 & 2.308 & 22.102 & 3.412 & 0.001 \\ \text { te Slaa et al., 2003 } & 0.653 & 0.256 & 1.668 & -0.890 & 0.373 \\ \text { Vemeiren et al., 1993 } & 2.107 & 0.986 & 4.504 & 1.923 & 0.054 \\ & 3.181 & 1.281 & 7.896 & 2.495 & 0.013\end{array}$

Figure 3 Sex and recurrent instability.
Statistics for each study

Odds ratio and $95 \% \mathrm{Cl}$

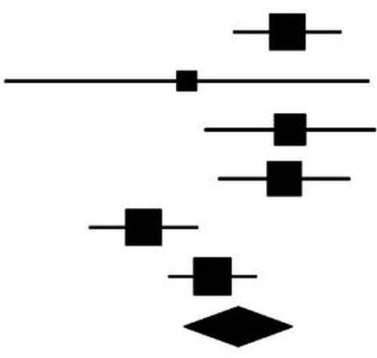

0.01

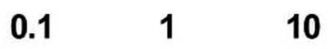

100

Favours Males

Favours Females
Study name

Salomonsson et al., 2009
Robinson et al., 2006
Pevny et al., 1998
Krallinger et al., 2002
Vermeiren et al., 1993
te Slaa et al., 2003
Hoelen et al., 1990

Statistics for each study

Odds Lower Upper

ratio limit limit Z-Value $p$-Value

$\begin{array}{lllll}0.164 & 0.007 & 3.586 & -1.149 & 0.250\end{array}$

$\begin{array}{lllll}0.194 & 0.024 & 1.560 & -1.541 & 0.123\end{array}$

$\begin{array}{lllll}0.771 & 0.034 & 17.319 & -0.163 & 0.870\end{array}$

$\begin{array}{lllll}0.124 & 0.037 & 0.413 & -3.399 & 0.001\end{array}$

$\begin{array}{lllll}0.112 & 0.015 & 0.864 & -2.100 & 0.036\end{array}$

$\begin{array}{lllll}0.124 & 0.007 & 2.162 & -1.432 & 0.152\end{array}$

$\begin{array}{lllll}0.035 & 0.002 & 0.582 & -2.336 & 0.019\end{array}$

$\begin{array}{llll}0.135 & 0.061 & 0.296 & -4.992\end{array}$

0.000

Figure 4 Greater tuberosity fractures and recurrent instability.

\section{Study name}

Salomonsson et al., 2009
Veimeren et al., 1993
Pevny et al., 1998
Hoelen et al., 1990

\section{Statistics for each study}

$\begin{array}{lcrrr}\begin{array}{c}\text { Odds } \\ \text { ratio }\end{array} & \begin{array}{c}\text { Lower } \\ \text { limit }\end{array} & \begin{array}{c}\text { Upper } \\ \text { limit }\end{array} & \text { Z-Value } & \text { p-Value } \\ 0.163 & 0.034 & 0.792 & -2.250 & 0.024 \\ 0.730 & 0.079 & 6.738 & -0.277 & 0.782 \\ 3.880 & 0.144 & 104.328 & 0.807 & 0.419 \\ 0.718 & 0.150 & 3.432 & -0.415 & 0.678 \\ 0.512 & 0.172 & 1.527 & -1.201 & 0.230\end{array}$

\section{Odds ratio and $95 \% \mathrm{Cl}$}

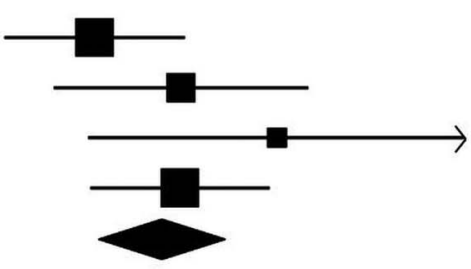

0.01
Odds ratio and $95 \% \mathrm{Cl}$

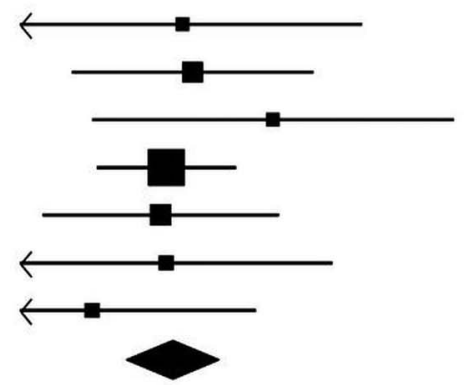

0.01

0.1

1

Favours No Greater

Favours Greater Tuberosity fracture

Figure 5 Bony Bankart lesions and recurrent instability. 
Study name

$\begin{array}{lcrrrrr} & \begin{array}{r}\text { Odds } \\ \text { ratio }\end{array} & \begin{array}{c}\text { Lower } \\ \text { limit }\end{array} & \begin{array}{r}\text { Upper } \\ \text { limit }\end{array} & \text { Z-Value } & \text { p-Value } \\ \text { Robinson et al., 2006 } & 0.181 & 0.040 & 0.811 & -2.233 & 0.026 \\ \text { Pevny et al., 1998 } & 2.067 & 0.085 & 50.036 & 0.446 & 0.655 \\ & 0.401 & 0.043 & 3.762 & -0.800 & 0.424\end{array}$

Odds ratio and $95 \% \mathrm{Cl}$

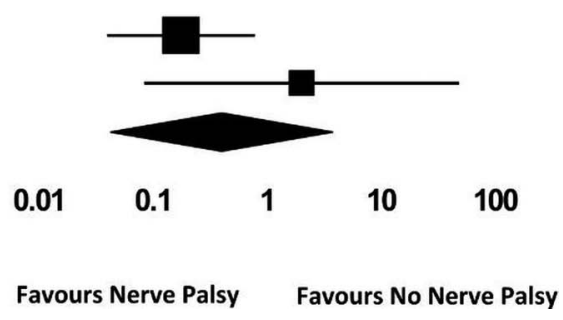

Figure 6 Nerve palsy and recurrent instability.

Study name

Robinson et al., 2006

Salomonsson et al., 2009
Statistics for each study

Odds Lower Upper ratio

$\begin{array}{rrrrr}2.680 & 1.261 & 5.694 & 2.564 & 0.010 \\ 2.667 & 0.414 & 17.169 & 1.032 & 0.302 \\ 2.678 & 1.332 & 5.385 & 2.764 & 0.006\end{array}$

Odds ratio and $95 \% \mathrm{Cl}$

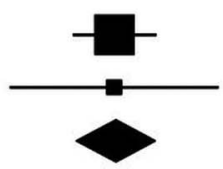

0.01

0.1

1

10

100

Favours Hyperlaxity

Figure 7 Hyperlaxity and recurrent instability.

\section{Study limitations}

Cohort studies are required to examine risk factors as they encapsulate a representative sample of the population and allow analysis of multiple variables. However, a limitation of these types of studies is the degree of bias present. Retrospective studies are limited by historical accuracy due to recall bias, imperfect information within medical records and loss to follow-up. ${ }^{18}$ Limitations of prospective studies include a difficulty in controlling for bias and a loss to follow-up. ${ }^{18}$

Although all studies in this review were appraised for methodological quality, no participants were excluded based on methodological quality as per recommendations of the Cochrane review. ${ }^{25}$ The inclusion of lower quality studies in this meta-analysis may have affected the results of this study. However, the calculation of the heterogeneity of variables highlights the variability among the studies. Where the results of lower quality studies differ from higher quality studies, this has been documented. The use of the GRADE system to categorise the quality of agreement and strength of evidence across all qualities of studies adds to the strength of this paper. ${ }^{47}$

\section{CLINICAL SUMMARY AND CONCLUSION}

We report that the average rate of recurrent instability 1 year following a first-time traumatic anterior shoulder dislocation is $39 \%$ (minimum $=4 \%$, maximum $=60 \%$ ). People aged 40 years and under were 13 times more likely to experience recurrent instability and men were three times more likely to than women. People with a greater tuberosity fracture were seven times less likely to experience recurrence when compared with those without a greater tuberosity fracture. People with hyperlaxity were nearly three times more likely to experience recurrent instability compared with those without hyperlaxity (table 7).

The rate of recurrent instability decreased as time from the initial dislocation increased. Other factors such as a bony Bankart lesion, nerve palsy and occupation were shown to influence rates of recurrent instability. Further evidence is required to investigate the influence of large Hill Sachs lesions, hyperlaxity and physiotherapy treatment on recurrent shoulder instability and the combined effect of these variables.

Thus, a range of variables may predict recurrent instability following a first-time traumatic anterior shoulder dislocation. Further research is required to establish a valid and reliable predictive tool weighted according to the strength of evidence of each variable. This tool can then be used by healthcare professionals to predict customised risk rates for groups of people depending on their profile.

It would be premature to conclude that those people who are at increased risk of recurrent instability are necessarily good candidates for surgical intervention, given the presence of confounders such as hypermobility in this group. The next step is to

Table 7 Summary of risk factors and relationship with recurrent instability

\begin{tabular}{ll}
\hline Risk factor & Rate of recurrence \\
\hline Aged 40 years and under & 13 times more likely \\
Men & 3 times more likely \\
Greater tuberosity fracture & 7 times less likely \\
Hyperlaxity & 3 times more likely \\
\hline
\end{tabular}


develop a predictive algorithm as outlined above. If the algorithm proves useful, it may then be time for an RCT of surgery and conservative management in those who are deemed at high risk of recurrence. In complex clinical scenarios, such as after first-time shoulder dislocation, shared decision-making with appropriate patient decision aids must be part of patient management. ${ }^{48}$

\section{What are the new findings?}

- Men are 3.2 times more likely to suffer from recurrent instability following a first-time traumatic anterior shoulder dislocation than women $(47.3 \%$ and $25.5 \%$, respectively).

- People 40 years and under are 13.5 times more likely to suffer recurrent instability following a first-time traumatic anterior shoulder dislocation than those over the age of 40 years.

- People with a greater tuberosity fracture are over seven times less likely to suffer from recurrent instability compared with people without a fracture.

- People with hyperlaxity are 2.7 times more likely to suffer from recurrent instability following a first-time traumatic anterior shoulder dislocation compared with people without hyperlaxity.

\section{How might it impact on clinical practice in the near} future?

- This paper supports previously known risk factors of age, tuberosity fractures, hyperlaxity and emphasises the impact of sex within the younger age categories.

- This paper provides data that can be used to inform patients with a first-time anterior shoulder dislocation regarding expectations from conservative management.

- Further research is required to develop a valid and reliable tool to predict recurrent shoulder instability after a first-time traumatic anterior shoulder dislocation.

- More effective conservative management strategies need to be developed for men who are 40 years and under, without a greater tuberosity fracture and are within 2 years of the initial dislocation.

Bob McCormack's podcast on first time shoulder dislocation: http://tinyurl.com/ozqkmy7

Contributors MO designed the study, collected and extracted and appraised data, designed the statistical analysis, analysed the data and drafted and revised the paper. RE monitored data extraction, assisted with methods development, helped draft and revise the manuscript. KD assisted with data extraction and analysis. PP assisted with statistical design and data analysis. PK monitored data extraction, assisted with methods development, helped draft and revise the manuscript and adjudicated when consensus was required regarding study inclusions and rating quality.

Funding This research received no specific grant from any funding agency in the public, commercial or not-for-profit sectors.

Competing interests None.

Provenance and peer review Not commissioned; externally peer reviewed. Data sharing statement No additional data are available.

- References to this paper are available online at http://bjsm.bmj.com
Open Access This is an Open Access article distributed in accordance with the Creative Commons Attribution Non Commercial (CC BY-NC 4.0) license, which permits others to distribute, remix, adapt, build upon this work non-commercially, and license their derivative works on different terms, provided the original work is properly cited and the use is non-commercial. See: http://creativecommons.org/ licenses/by-nc/4.0/

\section{REFERENCES}

1 Zacchilli MA, Owens BD. Epidemiology of shoulder dislocations presenting to emergency departments in the United States. J Bone Joint Surg Am 2010;92:542-9.

2 Leroux T, Wasserstein D, Veillette C, et al. Epidemiology of primary anterior shoulder dislocation requiring closed reduction in Ontario, Canada. Am J Sports Med 2014;42:442-50.

3 te Slaa RL, Brand R, Marti RK. A prospective arthroscopic study of acute first-time anterior shoulder dislocation in the young: a five-year follow-up study. I Shoulder Elbow Surg 2003;12:529-34.

4 Rowe C. Prognosis of dislocations of the shoulder. J Bone Joint Surg 1956;38-A:957.

5 Boone JL, Arciero RA. First-time anterior shoulder dislocations: has the standard changed? Br J Sports Med 2010;44:355-60.

6 Davy A, Drew S. Management of shoulder dislocation-are we doing enough to reduce the risk of recurrence? Injury 2002;33:775-9.

7 Kirkley A, Werstine R, Ratjek A, et al. Prospective randomized clinical trial comparing the effectiveness of immediate arthroscopic stabilization versus immobilization and rehabilitation in first traumatic anterior dislocations of the shoulder: long-term evaluation. Arthroscopy 2005;21:55-63.

8 Sachs $R$, Lin D, Stone M-L, et al. Can the need for future surgery for acute traumatic anterior shoulder dislocation be predicted? J Bone Joint Surg Am 2007;89:1665.

9 Cameron KL, Mountcastle SB, Nelson BJ, et al. History of shoulder instability and subsequent injury during four years of follow-up: a survival analysis. J Bone Joint Surg Am 2013;95:439-45.

10 Cameron KL, Duffey ML, DeBerardino TM, et al. Association of generalized joint hypermobility with a history of glenohumeral joint instability. J Athl Train 2010;45:253-8.

11 Robinson $\mathrm{CM}$, Howes J, Murdoch $\mathrm{H}$, et al. Functional outcome and risk of recurrent instability after primary traumatic anterior shoulder dislocation in young patients. J Bone Joint Surg Am 2006;88:2326.

12 Cheng S-C, Sivardeen ZA, Wallace WA, et al. Shoulder instability in professional rugby players: The significance of shoulder laxity. Clin I Sports Med 2012;22:397-402.

13 Ranalletta $M$, Bongiovanni S, Suarez $F$, et al. Do patients with traumatic recurrent anterior shoulder instability have generalized joint laxity? Clin Orthop Relat Res 2012;470:957-60.

14 Chahal J, Leiter J, McKee MD, et al. Generalized ligamentous laxity as a predisposing factor for primary traumatic anterior shoulder dislocation. J Shoulder Elbow Surg 2010;19:1238-42.

15 Kralinger FS, Golser K, Wischatta R, et al. Predicting recurrence after primary anterior shoulder dislocation. Am J Sports Med 2002;30:116.

16 Simonet WT, Cofield RH. Prognosis in anterior shoulder dislocation. Am J Sports Med 1984;12:19

17 de Smedt A, Hoogmartens M, Mulier JC. Recurrent anterior dislocation of the glenohumeral joint. Acta Orthop Belg 1975;41:215-26.

18 Gordis L. Epidemiology. 5th edn. Philadelphia: Elsevier Saunders, 2013.

19 Robinson CM, Aderinto J. Current concepts review: recurrent posterior shoulder instability. J Bone Joint Surg Am 2005;87:883-92.

20 Cordischi K, Li X, Busconi B. Intermediate outcomes after primary traumatic anterior shoulder dislocation in skeletally immature patients aged 10 to 13 years. Orthopedics 2009;32:686-90.

21 SIGN. Methodology checklist 3: cohort studies. SIGN, 2012. http://www.sign.ac.uk/ methodology/checklists.html

22 Perestelo-Perez L. Standards on how to develop and report systematic reviews in Psychology and Health. Int J Clin Health Psychol 2013;13:49-57.

23 SIGN. SIGN 50: a guideline developer's handbook. SIGN, 2011. http://www.sign.ac. uk/guidelines/fulltext/50/

24 Juni $\mathrm{P}$, Witschi $\mathrm{A}$, Bloch $\mathrm{R}$, et al. The hazards of scoring the quality of clinical trials for meta-analysis. J Am Med Assoc 1999;282:1054-60.

25 Higgins JPT, Green S. Cochrane Handbook for Systematic Reviews of Interventions The Cochrane Collaboration, 2009. http://www.cochrane-handbook.org

26 Borenstein M, Hedges L, Higgins J, et al. Comprehensive meta-analysis version 2. Engelwood, NJ: Biostat, 2005.

27 Higgins JPT, Thompson SG, Deeks JJ, et al. Measuring inconsistency in meta-analyses. BMJ 2003;327:557-60.

28 Salomonsson B, Heine A, Dahlborn M, et al. Bony Bankart is a positive predictive factor after primary shoulder dislocation. Knee Surg Sports Traumatol Arthrosc 2009;18:1425-31. 
29 Pevny T, Hunter R, Freeman J. Primary traumatic anterior shoulder dislocation in patients 40 years of age and older. Arthroscopy 1998;14:289-94.

30 Hoelen MA, Burgers AMJ, Rozing PM. Prognosis of primary anterior shoulder dislocation in young adults. Arch Orthop Trauma Surg 1990;110:51-4.

31 Vermeiren J, Handelbrg PP, Casteleyn PP, et al. The rate of recurrence of traumatic anterior dislocation of the shoulder. Int Orthop 1993;17:337-41.

32 Safran 0, Milgrom C, Radeva-Petrova DR, et al. Accuracy of the anterior apprehension test as a predictor of risk for redislocation after a first traumatic shoulder dislocation. Am J Sports Med 2010;38:972-5.

33 Wheeler JH, Ryan J, Arciero RA, et al. Arthroscopic versus nonoperative treatment of acute shoulder dislocations in young athletes. Arthroscopy 1989;5:213-17.

34 Bottoni CR, Wilckens JH, DeBerardino TM, et al. A prospective, randomized evaluation of arthroscopic stabilization versus nonoperative treatment in patients with acute, traumatic, first-time shoulder dislocations. Am I Sports Med 2002;30:576-80.

35 Jakobsen BW, Johannsen HV, Suder P, et al. Primary repair versus conservative treatment of first-time traumatic anterior dislocation of the shoulder: a randomized study with 10-Year follow-up. Arthroscopy 2007;23:118-23.

36 Doll $\mathrm{R}$, Hill $A B$. Lung cancer and other causes of death in relation to smoking. BMJ 1956;2:1071-81

37 Hovelius L, Olofson A, Sandstrom B, et al. Nonoperative treatment of primary anterior shoulder dislocation in patients forty years of age and younger. A prospective twenty-five year follow-up. J Bone Joint Surg Am 2008;90:945-52.

38 McLaughlin HL, Cavallaro WU. Primary anterior dislocation of the shoulder. Am J Surg 1950;80:615-21.
39 Owens BD, Agel J, Mountcastle SB, et al. Incidence of glenohumeral instability in collegiate athletics. Am I Sports Med 2009;37:1750-4.

40 Keeler LA. The differences in sport aggression, life aggression, and life assertion among adult male and female collision, contact, and non-contact sport athletes. J Sport Behav 2007;30:57-76.

41 Lee T, Dettling J, Sandusky M, et al. Age related biomechanical properties of the glenoid-anterior band of the inferior glenohumeral ligament-humerus complex. Clin Biomech (Bristol, Avon) 1999;14:471-6.

42 Buckwalter JA, Woo SL-Y. Age-related changes in ligaments and joint capsules: implications for participation in sports. Sports Med Arthrosc 1996;4:250-62.

43 Hovelius L, Eriksson $\mathrm{K}$, Fredin $\mathrm{H}$, et al. Recurrences after initial dislocation of the shoulder. Results of a prospective study of treatment. J Bone Joint Surg Am 1983:65:343-9.

44 Baker CL, Uribe JW, Whitman C. Arthroscopic evaluation of acute initial anterior shoulder dislocations. Am J Sports Med 1990;18:25-9.

45 Robinson CM, Kelly M, Wakefield AE. Redislocation of the shoulder during the first six weeks after a primary anterior dislocation: risk factors and results of treatment. J Bone Joint Surg Am 2002;84:1552-9.

46 Di Giacomo G, Itoi E, Burkhart SS. Evolving concept of bipolar bone loss and the Hill-Sachs lesion: from "engaging/non-engaging" lesion to "on-track/off-track" lesion. Arthroscopy 2004;30:90-8.

47 Guyatt GH, Oxman AD, Vist GE, et al. GRADE: an emerging consensus on rating quality of evidence and strength of recommendations. BMJ 2008;336:924-6.

48 Hoffman TC, Montori VM, Del Mar C. The connection between evidence-based medicine and shared decision making. JAMA 2014;312:1295-6. 